\title{
Forum
}

\section{Radial artery cannulation and ischaemic damage: a review}

R.G. Wilkins, MB, ChB, FFARCS, Instructor of Anesthesiology, University of Michigan Medical Center, Ann Arbor, MI 48109, USA, and Senior Registrar in Anaesthesia, University Department of Anaesthesia, University Hospital of South Manchester, Nell Lane, Manchester M20 8LR, England

Now Consultant Anaesthetist, University Hospital of South Manchester.

\section{Summary}

A review of the literature concerning ischaemic complications following radial artery cannulation suggests that the Allen test has little predictive validity. Other methods of assessing the ulnar collateral circulation are discussed.

\section{Key words}

Complications; thrombosis.

Arteries; radial.

Arterial cannulation is now performed widely, during major surgery or in intensive care to permit continuous monitoring of the systemic blood pressure and estimation of arterial blood gases. The commonest approach is percutaneous cannulation of the radial artery at the wrist.'

Occlusion of the radial artery may follow arterial cannulation, and if the ulnar collateral circulation is inadequate, may lead to ischaemic damage to the hand. ${ }^{1}$ The adequacy of the ulnar collateral circulation is generally assessed by the Allen test, first described in 1929 as a means of assessing the circulation in patients suffering from thrombo-angiitis obliterans. ${ }^{2}$

This paper reviews the literature concerning the incidence of ischaemic complications following radial artery cannulation, critically assesses the validity of the
Allen test, and discusses possible alternative methods of assessing the collateral circulation and of minimising the risk of ischaemic damage.

\section{Incidence of ischaemic complications}

All the reports which have described the complications following radial artery cannulation have stressed the high incidence (about $20 \%$ ) of early radial artery occlusion and the rarity of late ischaemic damage. ${ }^{3-12} \mathrm{Re}-$ cannulation of the occluded artery generally occurs, but may take several weeks. ${ }^{5}$ Results drawn from experience obtained in the early 1970s, when arterial cannulation became common, and from a decade later, are shown in Table 1.

However, case reports describing the occurrence

Table 1. The incidence of ischaemic complications following radial artery cannulation

\begin{tabular}{lcrcc}
\hline Series & Year & Cases & $\begin{array}{c}\text { Percentage with } \\
\text { temporary occlusion }\end{array}$ & $\begin{array}{c}\text { Cases of permanent } \\
\text { ischaemic damage }\end{array}$ \\
\hline $\begin{array}{l}\text { Zorab } \\
\quad \text { (Compilation) }\end{array}$ & 1969 & 1500 & - & 0 \\
Brown & & 8 & 0 \\
Bedford $^{3}$ & 1969 & 91 & 38 & 0 \\
Downs $^{6}$ & 1973 & 105 & 26 & 0 \\
Evans $^{7}$ & 1973 & 35 & 22 & 0 \\
Kim $^{8}$ & 1975 & 131 & 23 & 0 \\
Davis $^{\text {Jones }}{ }^{10}$ & 1975 & 95 & 24 & 0 \\
Russell $^{11}$ & 1980 & 333 & 5 & 0 \\
Slogoff & 1981 & 40 & 4 & 0 \\
Totals & 1982 & 178 & 25 & 0 \\
(excluding Zorab & & & \\
\hline
\end{tabular}


of permanent ischaemic damage following radial artery cannulation have been published. ${ }^{13-21}$ In the majority of these reports, there were additional factors present which may have contributed to the onset of tissue necrosis. These include emboli originating from a proximal site, ${ }^{13.16 .17}$ excessive trauma from very long or large-bore cannulae, ${ }^{18.21}$ prolonged shock, ${ }^{14,16,17,18,21}$ hyperlipoproteinaemia, ${ }^{14}$ or prior vascular disease. ${ }^{19}$

Reports of permanent ischaemic damage attributable solely to radial artery cannulation are apparently few, ${ }^{\text {s }}$ but aggressive management-for example brachial plexus or stellate ganglion block, 9,18 or surgical exploration, ${ }^{18.22}$-may be required to avoid permanent necrosis if arterial occlusion causes any sign of ischaemia.

In spite of the extremely small risk of permanent ischaemic damage following radial artery cannulation in patients lacking other contributory risk factors, the question remains of the feasibility of avoiding necrosis in patients with pre-existing risk factors or those who are likely to develop such contributory factors. Several approaches may be considered. Attempts may be made to confirm the presence of ulnar collateral flow, by the use of an Allen test or other technique, so that no area of the hand is seriously at risk should permanent radial artery occlusion occur. If the patient's history and the findings at general examination suggest an increased risk of arterial occlusion (e.g. the presence of hyperlipoproteinaemia), cannulation of the radial artery could be avoided. Additionally, consideration could be given to those aspects of the cannulation technique thought to be associated with an increased risk of occlusion and these factors avoided whenever possible.

\section{Assessing the collateral circulation}

\section{The Allen test}

A commonly preferred modification of the Allen test is as follows. The patient is required to make a tight fist, whilst the examiner occludes both uinar and radial arteries with his fingers. The patient's hand is then opened, and ulnar pressure is released. Ulnar collateral adequacy is shown by immediate erythematous blushing of the entire palmar surface of the hand and fingers. Blushing within 7 seconds is graded normal, 8-14 seconds slow or equivocal, and more than 15 seconds abnormal. 9 Modifications of this test have been described. ${ }^{23-27}$

An ideal test produces neither false positive nor false negative results. In the case of the Allen test, a false positive result would indicate normal flow but the absence of a collateral blood supply might lead to subsequent ischaemic damage. A false negative result would indicate an abnormal flow leading to denial of the benefits of radial artery cannulation. when, had cannulation been performed, no ischaemic damage would have followed.

Evaluation of the incidence of a false positive result, with permanent ischaemic damage occurring following a normal Allen test result, is difficult because the total number of cases of necrosis is small and other potentially causative factors complicate the situation. However, in the majority of cases of permanent damage described, ${ }^{12-16.18 .20}$ the Allen test result was quoted as normal.

A few authors have proceeded to cannulate the radial artery despite an abnormal result with the Allen test. Slow or equivocal Allen test results do not appear to be associated with any significant risk to the hand, ${ }^{3.9}$ and even in the presence of a completely abnormal result, no permanent ischaemic damage occurred in 10 cannulations, ${ }^{9}$ in 16 cannulations, or in an estimated 68 cannulations. ${ }^{12}$

It could be argued that the Allen test is not designed to predict ischaemic damage after arterial cannulation, but to assess the adequacy of the collateral circulation in the hand. ${ }^{2}$ In these terms, it is associated with an $0.8 \%$ incidence of false positive results, and a $53 \%$ incidence of false negative, when compared with measurements of the systolic pressure in the thumb. ${ }^{28}$ However, from the patient's viewpoint, the risk-benefit equation is ischaemic damage versus benefits of monitoring and it seems that an apparently normal collateral circulation does not preclude ischaemic complications ${ }^{12-15.20 .22}$ nor does an abnormal result predict them. ${ }^{5,9.12}$

\section{Other tests}

Doppler ultrasonic flow probes ${ }^{29}$ have for several years been used to localise the radial artery prior to cannulation in children ${ }^{30.31}$ or in difficult adult cases. ${ }^{32,33}$ The Doppler probe can also be used to map out the adequacy of the ulnar collateral flow. ${ }^{9,31,34,35}$ Ultrasonic evaluation of the circulation of the hand has the advantage of requiring no patient cooperation, and the results suggest, in a series of 140 hands examined, ${ }^{34}$ the likelihood of ischaemic damage to be between 4.8 and 12.8 patients per thousand, with a possible risk in an additional 25 to 50 patients per thousand. The validity of the predictions was not, however, tested. Two patients in a series of 1000 , with normal Doppler evaluated collateral circulation, required surgical intervention to treat ischaemic changes after cannulation. $^{22}$ The use of plethysmography has also been examined. ${ }^{36.37}$ The results suggested the absence of an adequate collateral flow in $10 \%$ of hands; ${ }^{37}$ again, cannulation in these circumstances was not attempted, and therefore the validity of this prediction cannot be judged.

\section{Other predictors of ischaemic risk}

Other factors associated with an increased risk of 
arterial occlusion are female sex, ${ }^{8,9.12}$ low cardiac output states, ${ }^{1.9 .12 .16}$ use of vasoconstrictor drugs, ${ }^{9,12.16}$ and pre-existing peripheral vascular disease. ${ }^{12.19}$ Age has not been shown to be a relevant factor ${ }^{8.9}$ Wrist circumferences of less than $18 \mathrm{~cm}$ may carry increased risk. ${ }^{38}$

The clinical technique seems to be of some importance. Multiple attempts ${ }^{9.11}$ or haematoma formation ${ }^{9.12}$ give an adverse prognosis. Whether the artery is transfixed or threaded seems irrelevant, ${ }^{9,10,33}$ although 20 -gauge cannulae may be better than 18gauge, ${ }^{6.8 .39}$ and Teflon may be the best material for cannula construction. ${ }^{40}$ Cannulae should be short. ${ }^{8}$ If cannulation persists for more than 20 hours, the risk of temporary arterial occlusion may be markedly increased. $^{5}$ However, it has not proved possible to combine these associated factors into a useful predictive function. ${ }^{9}$

\section{Clinical management: conclusions}

The Doppler ultrasound examination of the arterial supply to the hand may be a better test for an abnormal collateral flow than the Allen test, ${ }^{34}$ but whether it is a good predictor of ischaemic damage is not known. The Allen test does not appear to be a valid predictor of ischaemic injury to the hand following radial artery cannulation. ${ }^{9.12}$ It might therefore be argued that it is wrong to deny patients the benefits which may accrue from radial artery cannulation, in spite of adverse results if these tests are performed. Inadequate collateral circulation in the hand is usually unilateral,, .34 and use of the better side could be considered. Other sites for arterial cannulation have their advantages and disadvantages, ${ }^{1}$ but should be considered if concern about ischaemic damage exists.

Cannulation should be as atraumatic as possible, minimising the number of arterial punctures ${ }^{9.11}$ and avoiding haematoma formation. ${ }^{9.12}$ A 20-gauge, short Teflon catheter should be used, ${ }^{6.8 .39 .40}$ and cannulation terminated as soon as is feasible. ${ }^{5}$

The patient's hand should be examined frequently; if signs of arterial occlusion, for example wave form damping $^{9}$ or decreased hand perfusion ${ }^{5,9}$ occur, the cannula should quickly be removed. ${ }^{8.11}$ If signs of ischaemia do not disappear, brachial plexus block ${ }^{9}$ or surgery ${ }^{7.12}$ should be considered. Occlusion of the radial artery may occur several days after cannula removal; ${ }^{5}$ patients should be examined carefully at frequent intervals to ensure detection of late ischaemic changes.

If these precautions are followed, no significant damage is likely to occur. Slogoff et al. ${ }^{12}$ concluded that 'radial artery cannulation is a low-risk, high-benefit method of patient monitoring that deserves wide clinical use'. Further investigation is required to determine whether more sophisticated tests could adequately predict the occurrence of ischaemia, al- though large scale studies will be needed in view of the rarity of permanent damage.

\section{References}

1. Wiclatts S. Practical procedures: How to cannulate a peripheral artery. British Journal of Hospital Medicine 1980; 23: 628-31.

2. ALLEN EV. Thromboangitis obliterans: methods of diagnosis of chronic occlusive arterial lesions distal to the wrist with illustrative cases. American Journal of Medical Science 1929; 178: 237-44.

3. ZORAB JSM. Continuous display of the arterial pressure. A simple manometric technique. Anaesthesia 1969; 24: 431-7.

4. Brown AE, Sweeney DB, Lumley J. Percutaneous radial artery cannulation. Anaesthesia 1969; 24: 532-6.

5. Bedrord RF, Wollman $H$. Complications of percutaneous radial-artery cannulation: an objective prospective study in man. Anesthesiology 1973; 38: 228-36.

6. Downs JB, Rackstein AD, Klein EF Jr, Hawkins IF Jr. Hazards of radial-artery catheterization. Anesthesiology 1973; 38: 283-6.

7. Evans PJD, KeRR JH. Arterial occlusion after cannulation. British Medical Journal 1975; 3: 197-9.

8. Kim JM, ARakawa $K$, Bliss J. Arterial cannulation: factors in the development of occlusion. Anesthesia and Analgesia Current Researches 1975: 54: 836-41.

9. Davis FM, Stewart JM. Radial artery cannulation. A prospective study in patients undergoing cardiothoracic surgery. British Journal of Anaesthesia 1980; 52: 41-7.

10. Jones RM, Hill aB, Nahrwold ML, Bolles RE The effect of method of radial artery cannulation on postcannulation blood flow and thrombus formation. Anesthesiology 1981; 55: 76-8.

11. Russell JA, Joel M, Hudson RJ, Mangano DT, SCHLOBOHM RM. Prospective evaluation of radial and femoral artery catheterization sites in critically ill adults. Critical Care Medicine 1983; 11: 936-9.

12. Slogoff S, Keats AS, Arlund C. On the safety of radial artery cannulation. Anesthesiology 1983; 59: 42-7.

13. VENDER JS, WATtS DR. Differential diagnosis of hand ischemia in the presence of an arterial cannula. Anesthesia and Analgesia 1982; 61: 465-8.

14. Cannon BW, Meshier WT. Extremity amputation following radial artery cannulation in a patient with hyperlipoproteinemia type V. Anesthesiology 1982; 56: 222-3.

15. Mangano DT, Hickey RF. Ischemic injury following uncomplicated radial artery catheterization. Anesthesia and Analgesia 1979; 58: 55-7.

16. SAMAAN HA. The hazards of radial artery pressure monitoring. Journal of Cardiovascular Surgery 1971; 12: $342-7$.

17. Hall R. Vascular injuries resulting from arterial puncture or catheterization. British Journal of Surgery 1971: 58: $513-6$.

18. Baker RJ, Chunprapaph B, Nyhus LM. Severe ischemia of the hand following radial artery catheterization. Surgery 1976; 80: 449-57.

19. Katz AM, Birnanum M, Moylan J, Pellett J. Gangrene of the hand and forearm: a complication of radial artery cannulation. Critical Care Medicine 1974; 2: 270-2.

20. PALM T. Evaluation of peripheral arterial pressure on the thumb following radial artery cannulation. British Journal of Anaesthesia 1977; 49: 819-24.

21. Wyatt R, Glaves I, CoOper DJ. Proximal skin necrosis after radial-artery cannulation. Lancet 1974 ; 1: 1135-8. 
22. Mandel. MA, Dauchot PJ. Radial artery cannulation in 1000 patients: precautions and complications. Journal of Hand Surgery 1977: 2: 482-5.

23. Barber JD, Wright DJ, Elels RH. Radial artery puncture: a simple screening test of the ulnar anastomotic circulation. Anaesthesia 1973; 28: 291 -2.

24. Meyer RM, Katele GV. The case for a complete Allen's Test. Anesthesia and Analgesia 1983: 62: $947-8$.

25. GandHi SK, Reynolds AC. A modification of Allen's Test to detect aberrant ulnar collateral circulation. Anesihesiology 1983; 59: 147-8.

26. GREENHOW DE. Incorrect performance of Allen's Test ulnar-artery flow erroneously presumed inadequate Anesthesiology 1972; 37: 356-7.

27. Gelberman RH, Blasingame JP. The timed Allen Test. Journal of Trauma 1981; 21: 477-9.

28. Husum B, Berthelsen P. Allen's Test and systolic arterial pressure in the thumb. British Journal of Anaesthesia 1981 53: 635-7.

29. RISOE C, WILLIE SO. Blood velocity in human arteries measured by a bidirectional ultrasonic doppler flowmeter. Acta Physiologica Scandinavica 1978; 103: 370-8.

30. Chinyanga HM, Smith JM. A modified doppler flow detector probe-an aid to percutaneous radial arterial cannulation in infants and small children. Anesthesiology 1979; 50: $256-8$.

31. Morray JP, Braniford HG, Barnes LF. Shenton M, FURMAN EB. Doppler-assisted radial artery cannulation in infants and children. Anesthesia and Analgesia 1984; 63: $346-8$

Anaesthesia, 1985, Volume 40, pages 899-901
32. MCLeskey CH, Mims GR. Doppler-assisted radial artery cannulation. Anesthesiology 1982; 57: A25.

33. RICH JM. Use of the ultrasound stethoscope blood flow detector for cannulation of a weakly palpable radial artery. Heart and Lung 1984; 13: 47-8.

34. Mozersky DJ, Buckley CJ, Hagood CO, Jr, Capps WF, Jr. Dannemiller FJ, Jr. Ultrasonic evaluation of the palmar circulation. A useful adjunct to radial artery cannulation. The American Journal of Surgery 1973; 126: $810-2$

35. Kamienski RW, Barnes RW. Critique of the Allen Test for continuity of the palmar arch assessed by Doppler ultrasound. Surgery, Gynaecology and Obstetrics 1976; 142: $86]-4$.

36. BRodsky JB. A simple method to determine patency of the ulnar artery intraoperatively prior to radial-artery cannulation. Anesthesiology 1975; 42: 6267.

37. Husum B, Palm T. Before cannulation of the radial artery: collateral arterial supply evaluated by straingauge plethysmography. Acta Anaesthesiologica Scandinavica 1980; 24: 412-4.

38. BEDFORD RF. Wrist circumference predicts the risk of radial-arterial occlusion after cannulation. Anesihesiology 1978; 48: $377-8$.

39. BEDFORD RF. Radial arterial function following percutaneous cannulation with 18 - and 20-gauge catheters. Anesthesiology 1977: 47: 37-9.

40. BEDFORD RF. Percutaneous radial-artery cannulationincreased safety using Tefion catheters. Anesihesiology 1975; 42: 219-22.

\section{Intravenous regional anaesthesia with ketamine}

J.F. Amiot, MD, Assistant, Ph. Bouju, MD, Assistant, J.H. Palacci, MD, Chief, Department of Anaesthesiology and E. Balliner, MD, Resident in Anaesthesiology, Robert Ballanger General Hospital, F-93602 Aulnay-sous-Bois, France.

\section{Summary}

Ketamine, $40 \mathrm{ml} 0.5 \%$ solution, was used in the technique of intravenous regional anaesthesia in 14 patients undergoing upper limb surgery. Satisfactory analgesia was obtained in 12 of the patients. The method is limited by the fact that all patients became unconscious within a few minutes of tourniquet release, and that this could not be prevented by naloxone.

\section{Key words}

Anaesthetic techniques, regional; total intravenous.

Anaesthetics, intravenous; ketamine.

Despite much work on the subject. little is known concerning the mechanism of action of ketamine. It seemed to the authors that ketamine might be a very useful drug to use for the technique of intravenous regional anaesthesia. It had not previously been used in this manner. 